\title{
Epidemiology, Pathogenesis, and Diagnostic Strategy of Diabetic Liver Disease in Japan
}

\author{
Yoshio Sumida ${ }^{1, *(\mathbb{0})}$, Toshihide Shima ${ }^{2}$, Yasuhide Mitsumoto ${ }^{2}$, Takafumi Katayama ${ }^{2}$, \\ Atsushi Umemura ${ }^{3}$, Kanji Yamaguchi ${ }^{3}$, Yoshito Itoh ${ }^{3}$, Masashi Yoneda ${ }^{1}$ and Takeshi Okanoue ${ }^{2}$ \\ 1 Division of Hepatology and Pancreatology, Department of Internal Medicine, Aichi Medical University, \\ Nagakute, Aichi 480-1195, Japan; yoneda@aichi-med-u.ac.jp \\ 2 Center of Gastroenterology and Hepatology, Saiseikai Suita Hospital, Osaka 564-0013, Japan; \\ shima0301d@suita.saiseikai.or.jp (T.S.); mitsumoto-gi@umin.ac.jp (Y.M.); t-kata@koto.kpu-m.ac.jp (T.K.); \\ okanoue@suita.saiseikai.or.jp (T.O.) \\ 3 Department of Gastroenterology and Hepatology, Graduate School of Medicine, Kyoto Prefectural \\ University of Medicine, Kyoto 602-8566, Japan; aumemura@koto.kpu-m.ac.jp (A.U.); \\ ykanji@koto.kpu-m.ac.jp (K.Y.); yitoh@koto.kpu-m.ac.jp (Y.I.) \\ * Correspondence: sumida.yoshio.500@mail.aichi-med-u.ac.jp; Tel.:+81-561-62-3311; Fax: +81-561-62-1508
}

Received: 24 April 2020; Accepted: 16 June 2020; Published: 18 June 2020

\begin{abstract}
Type 2 diabetes (T2D) is closely associated with nonalcoholic fatty liver disease (NAFLD). Nonalcoholic steatohepatitis (NASH), a severe form of NAFLD, can lead to cirrhosis, hepatocellular carcinoma (HCC), and hepatic decompensation. Patients with T2D have twice the risk of HCC incidence compared with those without T2D. Because the hepatic fibrosis grade is the main determinant of mortality in patients with NAFLD, identifying patients with advanced fibrosis using non-invasive tests (NITs) or imaging modalities is crucial. Globally, the fibrosis-4 index (FIB-4 index), NAFLD fibrosis score, and enhanced liver fibrosis test have been established to evaluate hepatic fibrosis. Two-step algorithms using FIB-4 index as first triaging tool are globally accepted. It remains unknown which kinds of NITs or elastography are best as the second step tool. In Japan, type IV collagen 7s or the CA-fibrosis index (comprising type IV collagen $7 \mathrm{~s}$ and aspartate aminotransferase (AST)) is believed to precisely predict advanced fibrosis in NAFLD. Patients with NAFLD who have high non-invasive test results should be screened for HCC or esophageal varices. Risk factors of rapid fibrosis progression in NAFLD includes age, severe obesity, presence of T2D, menopause in women, and a patatin-like phospholipase domain containing the 3 GG genotype. Patients with NAFLD who have these risk factors should be intensively treated with lifestyle modification or pharmacotherapies for preventing liver-related mortality.
\end{abstract}

Keywords: hepatic fibrosis; type IV collagen 7s; hepatocellular carcinoma; patatin-like phospholipase domain containing 3

\section{Introduction}

Obesity and type 2 diabetes (T2D) are major risk factors in the development of nonalcoholic fatty liver disease (NAFLD). NAFLD is histologically categorized as simple steatosis (nonalcoholic fatty liver: NAFL) and may progress to nonalcoholic steatohepatitis (NASH), characterized by hepatocytes degeneration and inflammation. The latter can advance to fibrosis, cirrhosis and hepatocellular carcinoma (HCC). Patients with T2D not only are at a high risk of developing NAFLD but also display a progression toward significant liver fibrosis that is double that observed in other patients with NAFLD [1,2]. Insulin resistance has been considered an important factor in the development and progression of NAFLD [3]. However, the determinants of this increased risk in patients with T2D 
are still unclear [4]. Obesity, T2D, hypertension and dyslipidemia have been observed in NAFLD, and higher rates of overall mortality, mortality related to liver and cardiovascular diseases (CVD) have been reported when T2D and NAFLD were present concomitantly [5,6]. The leading cause of mortality in NAFLD patients is CVD [7]. NAFLD is an independent risk factor of coronary sclerosis [8], atrial fibrillation [9], and left ventricular dysfunction [10,11]. In daily clinical practice, we should pay attention to CVD event and control other risk factors, such as hypertension, dyslipidemia, and T2D.

With the Westernization of the Japanese lifestyle, public interest in lifestyle-related diseases has increased rapidly. In 2007, the Japan Society of Diabetes Mellitus reported that among the causes of death for 18,385 individuals with diabetes, liver cancer was the leading cause (8.6\%), while death from liver cirrhosis also was very common (4.7\%), $13.3 \%$ of deaths among patients with diabetes were attributable to liver disease [12]; however, the prevalence of hepatitis virus infections and heavy drinking were not analyzed in this study. According to a nationwide survey (2001-2010) in Japan, liver-related disease (HCC and cirrhosis) is the third leading cause of mortality (9.3\%) in T2D [13]. Most Japanese people are not as obese as Caucasians, but NAFLD is becoming more common in Japan (24.6-34.7\% of the adult population) [14-16]. This phenomenon may be explained by higher prevalence of patatin-like phospholipase domain containing 3 (PNPLA3) G allele in Asia compared with western countries $[15,17]$. At present, NASH is one of the most important liver diseases in many countries, including Japan. Oxidative stress has a major role in the pathogenesis of NASH and fibrosis progression [18]. As we previously reported, serum thioredoxin (TRX) levels, an indicator of oxidative stress, are higher in patients with NASH than those with NAFL [19]. TRX levels were positively correlated with fibrosis stage in NASH. Several antioxidative agents are therapeutic options for NASH, including vitamin E [20,21], glutathione [22], probucol [23], and pentoxifylline [24].

In 2008, the Japan NASH Study Group (of which Takeshi Okanoue was a representative), which was supported by the Ministry of Labor and Welfare, started to study NAFLD/NASH. The purpose was to elucidate the epidemiology, pathophysiology, genetic backgrounds and long-term prognosis of NAFLD, and to develop noninvasive tests (NITs) for diagnosis of NASH.

In this review article we describe the present status of liver disease in people with diabetes in many countries, including Japan.

\section{Epidemiology of Fatty Liver}

The prevalence of NAFLD differs by ethnic group and diagnostic tools, ranging from $15 \%$ to $70 \%$ [25]. The worldwide prevalence of NAFLD is about 30-35\% [17]. Liver biopsy remains the "gold standard" for diagnosis of necro-inflammatory activity and location of fibrosis although it is an invasive procedure. Most epidemiological studies in NAFLD were identified using ultrasonography (US) of the liver or a combined US and serum liver test (alanine aminotransferase: ALT). However, US is sometimes unable to detect less than $30 \%$ liver fat content $[26,27]$. Serum ALT level frequently shows normal range, especially in advanced staged NASH (known as "burned-out NASH"). Thus, at present, the exact epidemiology of NAFLD with/without T2D is uncertain. Approximately $50-60 \%$ of T2D patients may have NAFLD [6,28-30].

The Japan Society of Ningen Dock (a health check-up organization) reported in 2008 that the prevalence of liver dysfunction, including fatty liver, was 31.9\% in men and $17.1 \%$ in women, based on a study carried out of 1,814,864 adult men and 1,236,903 adult women [31]. Kojima et al. reported that the prevalence of fatty liver detected by medical health checks increased year after year, from $12.6 \%$ in 1989 to 30.3\% in 1998 [32]. The majority of fatty liver disease comprises alcoholic fatty liver and NAFLD, including NASH. Hamaguchi et al. reported that the prevalence of NAFLD was $23.3 \%$ in Japanese adults [26]. There is a sex difference in the incidence of NAFLD; men are more likely than women to develop fatty liver. Racially, NAFLD prevalence in Asians is never lower than that in Caucasians. PNPLA3 genotype has been shown to play a significant role in NAFLD pathogenesis, progression of liver fibrosis and even in the development of HCC $[15,17,33,34]$. In the Japanese population, the prevalence of the risk allele in PNPLA3 is high, which might be one reason in this point $[17,33]$. There is also a 
sex difference in the age distribution of NAFLD. In our study the incidence of fatty liver remained unchanged for men from the 30s to the 60s, whereas in women, the prevalence of fatty liver increased gradually with age and, when women were in their 60 s and beyond, the prevalence reached a higher level than that of men.

\section{Prevalence of NAFLD in Patients with Diabetes/Impaired Glucose Tolerance}

NAFLD prevalence differs by glycemic status. Kojima et al. reported that the prevalence of fatty liver was $18.6 \%$ in subjects with normal glucose metabolism (fasting blood sugar (FBS) $<110 \mathrm{mg} / \mathrm{dl}$ ), $43.7 \%$ in borderline subjects $(110 \mathrm{mg} / \mathrm{dl} \leq \mathrm{FBS}<126 \mathrm{mg} / \mathrm{dl})$, and $53.3 \%$ patients with diabetes (FBS $\geq 126 \mathrm{mg} / \mathrm{dl}$ ). FBS $\geq 110 \mathrm{mg} / \mathrm{dl}$ was an independent risk factor for fatty liver [32]. In 8352 Japanese patients who received health check-ups from 2009 to 2010, the incidence of NAFLD was $25.6 \%$ in those with normal fasting glucose, $56.2 \%$ in those with impaired fasting glucose (IFG), and $68 \%$ in those with T2D [14]. The overall prevalence of NAFLD in Southeast Asia varies from $9 \%$ to $45 \%$ in the general population and 6-62\% in patients with T2D [35]. As described above, the diagnostic tools for the detection of NAFLD in individual studies is not uniform. In the National Health and Nutrition Examination Study in Japan, conducted in 2007, 8,900,000 (of the total Japanese population of around 130,000,000) people were strongly suspected of having diabetes; the number of people with an undeniable possibility of having diabetes was 13,200,000, and the number of people with some possibility of having diabetes was $22,100,000$, which was 1.6 -fold higher than 10 years earlier [36]. NAFLD often precedes the development of T2D [37]. Recently it has been considered that NAFLD is an early predictor and determinant for development of diabetes. NAFLD has been shown to increase the risk of diabetes by 1.6 to 6.8 times in meta-analyses [38,39]. Miyaaki et al. examined the relationship between the stage of hepatic fibrosis and the prevalence of diabetes in Japanese patients. In the mild fibrosis group, $42 \%$ were complicated with diabetes, but in the severe fibrosis (bridging fibrosis or cirrhosis) group, the prevalence was as high as $71 \%(p=0.02)$. Diabetes might be an important factor responsible for the development of hepatic fibrosis in NAFLD [40].

We reported the results of the rate of abnormal liver function tests in 5642 (male: 3164, female: 2346) Japanese patients with T2D (average age; men: $62.2 \mathrm{y}$, women: $64.8 \mathrm{y}$ ) in which alcohol consumption and frequency of hepatitis B (HBV) and C virus (HCV) infection were analyzed [41]. The positive rate of HBsAg was $1.7 \%$ (male: $1.8 \%$, female: $1.6 \%$ ) and of anti HCV Ab was 5.1\% (male: $5.1 \%$, female: $5.0 \%$ ); however, most patients who were HBsAg positive showed very low levels of serum HBV DNA $(<2.6 \log \mathrm{IU} / \mathrm{mL})$ and $38 \%$ of the patients who were anti-HCV positive were negative for HCV RNA. The frequencies of habitual drinkers (daily alcohol intake $>60 \mathrm{~g}$ for more than 5 years) were $6.9 \%$ in male and $0.9 \%$ in female. Among the patients with NAFLD, the frequency of NASH and advanced stage NASH was significantly higher in male patients with T2D than in male patients without T2D. From these results, we suspect that in more than $80 \%$ of patients in Japan with diabetes who have liver injury, the reason for the liver injury is NAFLD. The incidence of HCC was $1.8 \%(n=48)$ in males and $0.9 \%(n=19)$ in females.

\section{Risk of Cancer in Patients with NAFLD and Diabetes}

NAFLD is a slowly progressive disease. The progression of one fibrosis stage is every 14 years in NAFLD and every 7 years in NASH; however, in $20 \%$ of NASH cases, fibrosis progresses more rapidly [42]. The coexistence of NAFLD and T2D worsens the course of both T2D and NAFLD [43]. A few decades ago, it was established that there is a substantially increased risk of mortality from cirrhosis and HCC in patients with T2D [44,45]. One report showed that patients with diabetes had an approximately threefold higher risk of dying of chronic liver diseases (CLDs), mainly associated with NAFLD [46]. Multiple studies and meta-analyses have claimed that T2D is associated with an increased risk of cancer at several sites, including liver, pancreas, endometrium, colorectum, breast, bladder, and a decreased risk of prostate cancer [47]. 
Recently we reported a follow-up study (average of 4.5 years) of 3999 patients with T2D [48]. Expected deaths in patients with T2D were estimated using age-specific mortality rates in the general population of Japan. The all-cancer mortality was significantly higher in patients with T2D than in the general population (standardized mortality rate (SMR) 1.58, 95\% confidence interval (CI) 1.33-1.87). Among malignancies, HCC conferred the highest mortality risk in patients with T2D (SMR 3.57, 95\% CI 2.41-5.10). HCC-associated mortality risk in patients with T2D remained significantly high (SMR 2.56, 95\% CI 1.64-3.97) after adjusting for high positivity rates of hepatitis B surface antigen (1.7\%) and anti-hepatitis $C$ virus (5.3\%). In patients with T2D who have low platelet counts $\left(<200 \times 10^{3} / \mu \mathrm{L}\right)$, the SMR of HCC increased from 3.57 to 6.58 (95\% CI 4.34-9.58). Patients with T2D who have a platelet count $>200 \times 10^{3} / \mu \mathrm{L}$ showed no increase in mortality risk (SMR 0.68) of HCC. Our study is the first to demonstrate the significantly higher mortality of HCC in patients with T2D compared with the general population, even after adjusting for hepatitis virus positivity.

A Chinese cohort study showed that T2D was associated with an increased incidence of non-B, non-C HCC [49]. Patients with T2D are at high risk of NASH with liver fibrosis and are more likely to develop NASH-related cirrhosis and eventually NASH-related HCC [2,50-52]. The second cause was the increased HCC-associated mortality risk in patients with T2D who also have HBV or HCV hepatitis, especially in China, Taiwan and Korea. A study in Taiwan reported that T2D was significantly associated with an increased incidence of HCC in patients with HCV infection (risk ratio (RR), 3.52) and in HBV carriers (RR 2.27) [53]. A meta-analysis further supports the finding that T2D is a risk factor of HCC in patients with HCV infection (RR 1.90) and those with HBV infection (RR 1.69) [54]. Therefore, T2D might accelerate mortality in NASH-related and virus-associated HCC.

Patients with NASH who have advanced fibrosis are at a high risk of HCC [55,56]. The influence of insulin treatment on cancer risk is controversial. Although mechanisms of oncogenesis include insulin resistance, hyperinsulinemia, hyperglycemia, and inflammation $[47,48]$, previous studies suggested hyperinsulinemia as a central player in the association between T2D and cancer development and progression $[57,58]$. Exogenous insulin administration might be implicated in the pathogenesis of increased cancer risk [59]. Here the mortality rate of all cancers was comparable between insulin and no-medication groups. However, a more precise analysis of the type, dose, and duration of insulin is necessary for discussing this agenda. The JDS/Japanese Cancer Association Joint Committee on Diabetes and Cancer reported that there was limited evidence as to whether any particular antidiabetic agent might influence cancer risk [60]. The relationship between glycemic control and cancer risk has also been controversial. Here the all-cancer mortality was higher in patients with T2D who have low glycated hemoglobin $(\mathrm{HbA1c})(<7.0 \%)$ than in those with high $\mathrm{HbA1c}(\geq 7.0 \%)$ at the time of enrollment. Because $\mathrm{HbA} 1 \mathrm{c}$ levels in the patient cohort were not monitored during the follow-up period, this result should be carefully interpreted. A meta-analysis reported that there was no evidence to support the hypothesis that improved glycemic control reduces the risk of cancer incidence or mortality [61,62].

\section{The PNPL3 SNP and HCC- or Liver-Related Mortality}

The PNPLA3 GG genotype seems to have an approximately twofold higher risk of developing hepatic steatosis, a three- to four-fold higher risk of developing NASH and cirrhosis, and an up to 12 -fold higher risk of developing HCC as compared with the PNPL3 CC genotype [63]. In 110,761 individuals from the Danish general population and 334,691 individuals from the UK Biobank, the combination of PNPLA3, transmembrane 6, superfamily member 2 (TM6SF2) and hydroxysteroid 17-beta dehydrogenase 13 (HSD17B13) is associated with an up to 12-fold higher risk of developing cirrhosis and an up to 29-fold higher risk of developing HCC [64]. According to the U.S. National Health and Nutrition Examination Survey (NHANES), 1988-1994, with 27 years of linked mortality data, the PNPLA3 GG genotype had an 18-fold higher risk of developing liver-related mortality [65]. In previous studies, the PNPLA3 SNP did not play any role in obesity, insulin resistance, or incidence of T2D.

In Japan, we previously reported that severe hepatic fibrosis (F3/4) and PNPLA3 GG are significant factors associated with incident HCC development in Japanese patients with biopsy proven NAFLD [56]. 
A multicenter study from Japan by Korenaga and colleagues demonstrated that the SNPs of PNPLA3, when juxtaposed with another zinc finger protein 1 (JAZF1), were associated with development of HCC in patients with T2D who did not have hepatitis virus infection [66]. In addition, we newly identified rs17007417 in dysferlin $\left(p=5.2 \times 10^{-7}\right.$, OR $\left.(95 \% \mathrm{CI})=2.74(1.84-4.06)\right)$ as an SNP-associated with NASH-HCC [33] (Table 1). However, external validation studies are required to confirm this result.

Table 1. The distribution of SNPs in patatin-like phospholipase domain containing 3 (PNPLA3) and dysferlin in 58 Japanese patients with nonalcoholic steatohepatitis (NASH)-hepatocellular carcinoma (HCC) [33].

\begin{tabular}{|c|c|c|c|c|c|}
\hline & \multicolumn{4}{|c|}{ PNPLA3 } & \multirow[b]{2}{*}{ Total } \\
\hline & & $\begin{array}{c}\text { Major allele } \\
\text { (TT) } \\
29.4 \% *\end{array}$ & $\begin{array}{c}\text { Hetero } \\
\text { (TG) } \\
4 \% \text { * }\end{array}$ & $\begin{array}{c}\text { Risk allele } \\
\text { (GG) } \\
21.1 \% \text { * }\end{array}$ & \\
\hline \multirow{3}{*}{ DYSF } & $\begin{array}{c}\text { Major allele } \\
\text { (CC) } \\
68.5 \% \text { * }\end{array}$ & $\begin{array}{c}1 \\
(1.7 \%)\end{array}$ & $\begin{array}{c}7 \\
(12.1 \%)\end{array}$ & $\begin{array}{c}17 \\
(29.3 \%)\end{array}$ & $43 \%$ \\
\hline & $\begin{array}{l}\text { Hetero } \\
(\mathrm{CT}) \\
28.8 \% \text { * }\end{array}$ & $\begin{array}{c}4 \\
(6.9 \%)\end{array}$ & $\begin{array}{c}10 \\
(17.2 \%)\end{array}$ & $\begin{array}{c}11 \\
(19.0 \%)\end{array}$ & $43 \%$ \\
\hline & $\begin{array}{c}\text { Risk allele } \\
\text { (TT) } \\
2.6 \% \text { * }\end{array}$ & $\begin{array}{c}1 \\
(1.7 \%)\end{array}$ & $\begin{array}{c}1 \\
(1.7 \%)\end{array}$ & $\begin{array}{c}6 \\
(10.3 \%)\end{array}$ & $13.7 \%$ \\
\hline Total & & $10.3 \%$ & $31.0 \%$ & $58.6 \%$ & \\
\hline
\end{tabular}

* prevalence of the general population; PNPLA3: patatin-like phospholipase domain containing 3, DYSF: dysferlin.

\section{Noninvasive Tests for Diagnosis of NAFLD and Staging Fibrosis}

\subsection{Evaluation of Hepatic Steatosis}

US is the most common means for detecting hepatic steatosis; however, its sensitivity has been determined to be $85 \%$ [67] and its detection rate is lower if the hepatic steatosis is less than $30 \%$ [68]. Innovative imaging technologies for detecting mild steatosis ( $>5 \%$ of hepatocytes affected) have been developed, such as the vibration-controlled transient elastography (VCTE) controlled attenuation parameter (CAP), magnetic resonance imaging-proton density fat fraction (MRI-PDFF), and the ultrasound-guided attenuation parameter (UGAP) [69]. NITs for predicting steatosis in NAFLD have also been proposed to avoid imaging tests or biopsies (Table 2). The fatty liver index (FLI) [70], the SteatoTest [71] and the NAFLD liver fat score [72] reliably predict steatosis for severely obese people [73]. However, these biomarkers are not suitable for Asians because obesity is defined as a BMI $>25 \mathrm{~kg} / \mathrm{m}^{2}$ in Asian people but $>30 \mathrm{~kg} / \mathrm{m}^{2}$ in Western people. There are no validation studies of these NITs from Japan as so far, because US diagnosis is routinely performed by medical health check-up or general physicians in Japan. The FLI was validated by a study of 13,122 subjects in western China [74]. In Japan, the FLI is a useful predictor of incident diabetes [75]. 
Table 2. Non-invasive tests (NITs) for predicting steatosis in hepatic steatosis.

\begin{tabular}{|c|c|c|c|}
\hline Index & $\begin{array}{l}\text { Author } \\
\text { (Nation) }\end{array}$ & Publication (Year) & Parameters \\
\hline Fatty liver index (FLI) & $\begin{array}{l}\text { Bedogni } \\
\text { (Italy) }\end{array}$ & $\begin{array}{l}\text { BMC Gastroenterology } \\
\text { (2006) [70] }\end{array}$ & BMI, WC, TG, $\gamma$ GTP \\
\hline NAFLD liver fat score & $\begin{array}{l}\text { Kontronen } \\
\text { (Finland) }\end{array}$ & Gastroenterology (2009) [72] & MetS, T2D, IRI, AST, AST/ALT ratio \\
\hline $\begin{array}{l}\text { Hepatic steatosis index } \\
\text { (HSI) }\end{array}$ & $\begin{array}{c}\text { Lee } \\
\text { (Korea) }\end{array}$ & $\begin{array}{l}\text { Dig Liver Dis } \\
\text { (2010) [76] }\end{array}$ & $\begin{aligned} & 8 \times \text { AST/ALT ratio }+ \text { BMI } \\
&+(\text { female: }+2, \text { diabetes: }+2) \\
&\end{aligned}$ \\
\hline $\begin{array}{l}\text { SteatoTest } \\
\quad(\mathrm{ST})\end{array}$ & $\begin{array}{l}\text { Poynaud } \\
\text { (France) }\end{array}$ & $\begin{array}{l}\text { Comp Hepatol } \\
\text { (2005) [71] }\end{array}$ & $\begin{array}{l}\text { ALT, } \alpha 2 \text {-macroglobulin, apolipoprotein A-I, } \\
\text { haptoglobin, total bilirubin, } \gamma \mathrm{GTP}, \\
\text { cholesterol, TG, glucose, age, sex, BMI }\end{array}$ \\
\hline
\end{tabular}

BMI: body mass index, WC: waist circumference, TG: triglyceride, $\gamma$ GTP: gamma glutamyl transpeptidase, MetS: metabolic syndrome, T2D: type 2 diabetes, IRI: immune-reactive insulin, AST: aspartate aminotransferase, ALT: alanine aminotransferase.

A healthy ALT level is defined as 19 to $25 \mathrm{U} / \mathrm{L}$ for women and 29 to $33 \mathrm{U} / \mathrm{L}$ for men $[77,78]$. In our study with Japanese participants, these were 11 to $21 \mathrm{U} / \mathrm{L}$ for women and 13 to $24 \mathrm{U} / \mathrm{L}$ for men, and healthy people show an AST $>$ ALT within the normal range of AST and ALT. Thus, we consider that people with $>25 \mathrm{U} / \mathrm{L}$ of ALT in women, $>30 \mathrm{U} / \mathrm{L}$ of ALT in men and/or AST $<$ ALT within the normal range of ALT with a BMI of $>25 \mathrm{~kg} / \mathrm{m}^{2}$ are candidates for receiving NAFLD screening.

\subsection{Evaluation of Hepatic Fibrosis}

Advanced hepatic fibrosis is the most important risk factor for not only incident HCC but also liver-related mortality in NAFLD [79]. In patients with T2D, the prevalence of advanced fibrosis (F3/4) is estimated to be $17 \%$ (95\% CI 7.2-34.8\%) by liver biopsy [28,80], 7.3-24.9\% by VCTE and $4.3-7.1 \%$ by magnetic resonance elastography (MRE) [81]. All institutions do not have these innovative modalities such as VCTE or MRE. Therefore, it is important to establish simple, sensitive and low-cost NITs for the screening and staging of fibrosis in epidemiological study and in practice [82,83]. A reliable biochemical marker for advanced stages of NASH has not been established. Among a variety of NITs (Table 3), the fibrosis-4 index (FIB-4 index) and NAFLD fibrosis score (NFS) are the most appropriate to identify advanced fibrosis (F3/4) for general physicians (as first step) because these scoring systems consist of common parameters in daily clinical practice. Vilar-Gomez et al. reported that NFS and the FIB-4 index are useful screening tools for determining the stage of liver fibrosis to be routinely applied in clinical practice [84]. Thus, the FIB-4 index and NFS are now recommended for excluding advanced fibrosis (F3/4) in the American Association for the Study of Liver Diseases (AASLD) practice guidance 2018 [85]. NFS was calculated by the formula: $1.675+0.037 \times$ age (years) $+0.094 \times \mathrm{BMI}\left(\mathrm{kg} / \mathrm{m}^{2}\right)+1.13$ $\times$ impaired fasting glucose/diabetes (yes $=1$, no $=0)+0.99 \times$ AST/ALT ratio $-0.013 \times$ platelet count $\left(\times 10^{9} / \mathrm{L}\right)-0.66 \times$ albumin $(\mathrm{g} / \mathrm{dL})$ [86]. NFS is useful but too complex, because it requires six parameters. In contrast, the FIB-4 index has similar accuracy to the NFS and has only four parameters $[87,88]$. The FIB-4 index must be the most simple and cheapest test to define the stage of liver fibrosis. However, the FIB-4 index has also several drawbacks. First, low and high cutoff points are variable according to ethnics. Low cut-off value of FIB-4 index was generally accepted as 1.3 in Western countries [87], while it was 1.45 in Asia [88,89]. Second, FIB-4 index requires an intermediate group. NAFLD patients classified into that group have to receive other NITs or liver biopsies. Third, it is a concern that FIB-4 index may overpredict fibrosis in older patients $[90,91]$, because its formula includes age. On the basis of data in JSG-NAFLD, the new proposed low cutoff points are 1.88 in 60-69 years, and 1.95 in $\geq 70$ years [91]. Moreover, we found that FIB-4 index might be inferior in NAFLD patients with T2D compared to those without T2D [92]. Although its precise mechanism of inferiority in T2D patients remains unknown, platelet count tends to be higher in NAFLD patients with T2D compared to those without T2D. FIB-4 index in NAFLD patients with T2D is lower than in those without T2D at the same 
fibrosis stages. Fourth, Shah $\mathrm{S}$ and colleagues feel that a low cut-off of 1.3 may be inappropriate, as it would include patients with F2 fibrosis [93]. F2 fibrosis confers an increased mortality of liver-related diseases compared with no fibrosis (F0) (HR: 2.52) [79]. "Active NASH" which requires intensive treatment is defined as NASH with NAFLD activity score (NAS) $\geq 4$ and $\geq$ F2. FAST score, consisting of three parameters including VCTE-based CAP, VCTE-based LSM, and AST, can predict "active $\mathrm{NASH}^{\prime \prime}[94,95]$. However, the FIB-4 index is believed to be sufficient as a triaging tool to exclude advanced fibrosis (F3/F4).

Thus, we recently developed markers that were reliable (for screening NASH: the FM-NASH index; for staging liver fibrosis: the FM-fibro index) [96] and simple (for screening NASH: the CA index-NASH; for staging liver fibrosis: the CA index-fibrosis) [97] to screen NASH and to estimate advanced liver fibrosis in NASH. We consider that both the FM index and CA index are superior to other NITs. Especially, the CA index is very simple and highly accurate; it is composed of type IV collagen 7s and AST. Calculation of the CA index is shown as CA index-NASH $=0.994 \times($ type IV collagen $7 \mathrm{~s}(\mathrm{ng} / \mathrm{mL}))+0.0255 \times($ AST $(\mathrm{IU} / \mathrm{l}))$; and CA index-fibrosis $=1.5 \times($ type IV collagen $7 \mathrm{~s}$ $(\mathrm{ng} / \mathrm{mL}))+0.0264 \times($ AST $(\mathrm{IU} / \mathrm{l}))($ Table 3$)$. The CA index NASH, consisting of type IV collagen $7 \mathrm{~s}$ and AST, showed high AUROC (training: 0.857; validation: 0.769) [98] for differentiating between NAFL and NASH. We consider that type IV collagen $7 \mathrm{~s}$ is a central fibrosis marker in NASH. Type IV collagen $7 \mathrm{~s}$ is a fragment of collagen type IV, and it is part of the extracellular matrix, which forms the basement membrane. Type IV collagen $7 \mathrm{~s}$ is an established biochemical marker of liver fibrosis. An increase in serum levels of type IV collagen $7 \mathrm{~s}$ is accompanied by progression of liver fibrosis in various chronic types of hepatitis, including NASH. Additionally, the efficacy for diagnosis of advanced fibrosis in NASH has been established. A previous study showed the efficacy of type IV collagen 7s for diagnosing NASH or advanced fibrosis of NAFLD [99-101]. Type IV collagen 7s has been estimated by radioimmunoassay in Japan; however, from April 2020, it was able to be estimated by ELISA in Japan. A platelet count is a simpler marker for screening patients with T2D who are at high risk of HCC. Kawamura et al. identified a platelet count $<150 \times 10^{3} / \mu \mathrm{L}$ as a risk factor of HCC in patients with NAFLD (HR 7.19) [55]. Detection of patients with advanced hepatic fibrosis by monitoring platelet counts may be effective for early identification of those at high risk of HCC. A high FIB-4 index score $>2.67$ is also a useful marker for HCC risk (RR 14.0). Formula, strengths, and weakness in each NIT are summarized in Table 3.

Table 3. NITs for predicting fibrosis in nonalcoholic fatty liver disease (NAFLD).

\begin{tabular}{|c|c|c|c|}
\hline Index & Formula & Strengths & Weaknesses \\
\hline $\begin{array}{l}\text { FIB-4 index } \\
{[87,88,91]}\end{array}$ & $\begin{array}{c}\text { (age [years] } \times \text { AST [U/L]/(platelet } \\
\left.\text { count }\left[10^{9} / \mathrm{L}\right] \times \sqrt{\mathrm{ALT}}[\mathrm{U} / \mathrm{L}]\right) \\
\text { https://www.eapharma.co.jp/ } \\
\text { medicalexpert/product/livact/fib-4/ } \\
\text { calculator.html }\end{array}$ & $\begin{array}{c}\text { Simple } \\
\text { (only four parameters) } \\
\cdot \text { Accurate } \\
\cdot \text { Validated globally }\end{array}$ & $\begin{array}{c}\text { - Requires an intermediate group } \\
\text { - Overpredict in old patients } \\
\text { - Inferior in patients with T2D }\end{array}$ \\
\hline $\begin{array}{l}\text { NAFLD fibrosis } \\
\text { score [86] }\end{array}$ & $\begin{array}{c}-1.675+0.037 \times \text { age }(\text { years })+0.094 \times \\
\text { BMI }\left(\mathrm{kg} / \mathrm{m}^{2}\right)+1.13 \times \text { impaired fasting } \\
\text { glucose } / \text { diabetes }(\text { yes }=1, \text { no }=0)+ \\
0.99 \times \text { AST } / \text { ALT ratio }-0.013 \times \\
\text { platelet count }\left(\times 10^{9} / \mathrm{L}\right)-0.66 \times \\
\text { albumin }(\mathrm{g} / \mathrm{dL}) \\
\text { http://nafldscore.com/ }\end{array}$ & - Validated globally & $\begin{array}{c}\text { Complex } \\
\text { (six parameters) } \\
\cdot \text { Requires an intermediate group } \\
\text { - Overpredict in old patients }\end{array}$ \\
\hline $\begin{array}{l}\text { CA-fibrosis } \\
\text { index [97] }\end{array}$ & $\begin{array}{c}1.5 \times \text { type IV collagen } 7 \mathrm{~s}(\mathrm{ng} / \mathrm{mL})+ \\
0.0264 \times \text { AST }(\mathrm{IU} / \mathrm{l})\end{array}$ & $\begin{array}{c}\text { Simple } \\
\text { (only two parameters) }\end{array}$ & $\begin{array}{c}\text {. Only available in Japan } \\
\text {. No external validation studies }\end{array}$ \\
\hline ELF test [98] & $\begin{array}{c}-7.412+(\text { In }[\mathrm{HA}] \times 0.681)+(\mathrm{In} \\
[\mathrm{P} 3 \mathrm{NP}] \times 0.775)+(\mathrm{In}[\mathrm{TIMP} 1] \times 0.494)\end{array}$ & $\begin{array}{c}\cdot \text { Accurate } \\
\cdot \text { Validated globally }\end{array}$ & $\begin{array}{c}\cdot \text { High cost } \\
\text { (three parameters) }\end{array}$ \\
\hline
\end{tabular}

FIB-4: fibrosis-4, AST: aspartate aminotransferase, ALT: alanine aminotransferase, BMI: body mass index, HA: hyaluronic acid, P3NP: aminoterminal propeptide of type 3 procollagen. TIMP-1: tissue inhibitor of matrix metalloproteinase type 1, ELF: enhanced liver fibrosis. 
In conclusion, the FIB-4 index is believed to be sufficient for general physicians or endocrinologists as a triaging tool to exclude advanced fibrosis (F3/4). The CA-fibrosis and enhanced liver fibrosis (ELF) tests are useful for hepatologists (as a second step) to consider performing liver biopsy. Recently, two studies from Europe [102] and the US [103] demonstrated that VCTE controlled CAP and the liver stiffness measurement (LSM) in assessing steatosis and fibrosis in patients with suspected NAFLD. They found that CAP and LSM by FibroScan to assess liver steatosis and fibrosis with AUROC values ranged from 0.70 to 0.89 [84]; however, VCTE was less accurate in distinguishing a lower fibrosis stage, higher steatosis grades, or the presence of NASH [103]. In a few Japanese studies, 9.6-10.8 kPa of LSM was an optimal cutoff value for identifying advanced fibrosis in NAFLD [104-106].

\subsection{Combination of NITs and Imaging Modalities}

Recently, two systematic review articles covering the diagnosis of NASH and its staging of liver fibrosis were reported from the US [107] and Europe [108] in which Younossi et al. recommended a combination of biochemical NITs and MRE for the best predictive performance. We recently reported the usefulness of the combination of LSM by VCTE and NITs for the diagnosis of the stage of liver fibrosis in NASH. VCTE has a slightly limited applicability for patients with NAFLD; however, we demonstrated that using concurrent measurement with certain biomarkers to predict advanced liver fibrosis $(>F 3 / 4)$, such as the FM-fibro index (AUROC; 0.945), type IV collagen 7s (AUROC; 0.925), FIB-4 index (AUROC; 0.927) and CA fibro index (AUROC; 0.919), significantly improved the diagnostic accuracy [109]. We should establish the best combination of NITs and imaging studies from the perspective of the cost-benefit balance.

\section{Two-Step Algorithm in NAFLD Diagnosis}

For diagnosing NAFLD, a two-step algorithm is now globally accepted $[84,89,110,111]$, as shown in Figure 1. As the first step, patients with NAFLD who have a FIB-4 index $<1.3$ who are unlikely to have advanced stage (F3/4) can be followed up. The FIB-4 index should be measured every 2 or 3 years. As the second step, patients with NAFLD who have a FIB-4 index $\geq 1.3$ are recommended to receive VCTE. Patients with VCTE $\geq 10 \mathrm{kPa}$ have to undergo liver biopsy unless they have any contra-indications for performing liver biopsy, and subjects with VCTE $\leq 10 \mathrm{kPa}$ can be followed up with annual VCTE. One concern is that not all institutions have VCTE even in Japan. However, there are alternative NITs for evaluating hepatic fibrosis, including the type IV collagen 7s, CA-fibrosis index and ELF test. MR elastography is positioned as third step, considering its cost, duration, and contraindication in patients with pacemakers or claustrophobia. Better algorithms are expected to be developed from the point of view of accuracy, non-invasiveness, and cost-benefit balance owing to the huge number of people with NAFLD. Because the FIB-4 index is influenced by age, some reports have suggested a low cutoff value of 2.0 in older patients (aged 65 to $70 \mathrm{y}$ or older) $[90,91]$. Old NAFLD patients showing FIB-4 index $<2.0$ are unlikely to have advanced fibrosis.

It remains to be resolved which is the best modality as the second step among a variety of NITs. VCTE is recommended as the second step, considering its simplicity, portability, and non-invasiveness. In a few Japanese studies, 9.6-10.8 kPa of LSM was an optimal cutoff value for identifying advanced fibrosis in NAFLD [104-106]. A two-step referral pathway system from Canada suggested that the cutoff value of VCTE was $8.0 \mathrm{kPa}$ after triaging by FIB-4 index [111]. An international collaboration study showed that the optimal threshold of VCTE for detection of advanced fibrosis (F3/F4) was $8.8 \mathrm{kPa}$ [112]. Thus, the cutoff values of VCTE for identifying advanced fibrosis varied from 8.0 to $10.8 \mathrm{kPa}$. In this two-step algorithm, $10.0 \mathrm{kPa}$ was adapted as the cutoff values of VCTE for identifying advanced fibrosis. However, this two-step algorithm should be validated by international, multi-center, and prospective trials. Other candidates as the second step modality include type IV collagen 7S, CA-fibrosis index, Mac-2 binding protein glycan isomer (M2BPGi) [113] and ELF test [114]. M2BPGi, a novel hepatic fibrosis marker, has been developed in Japan. M2BPGi can predict fibrosis stage in CLD, including NAFLD [115-117]. In the Korean population with CLD, sequential combination 
of FIB-4 index followed by M2BPGi can identify advanced fibrosis ( $\geq$ F3) evaluated by MRE [113]. We are now planning to validate this two-step algorithm using FIB-4 index and M2BPGi in Japanese population with biopsy-proven NAFLD.

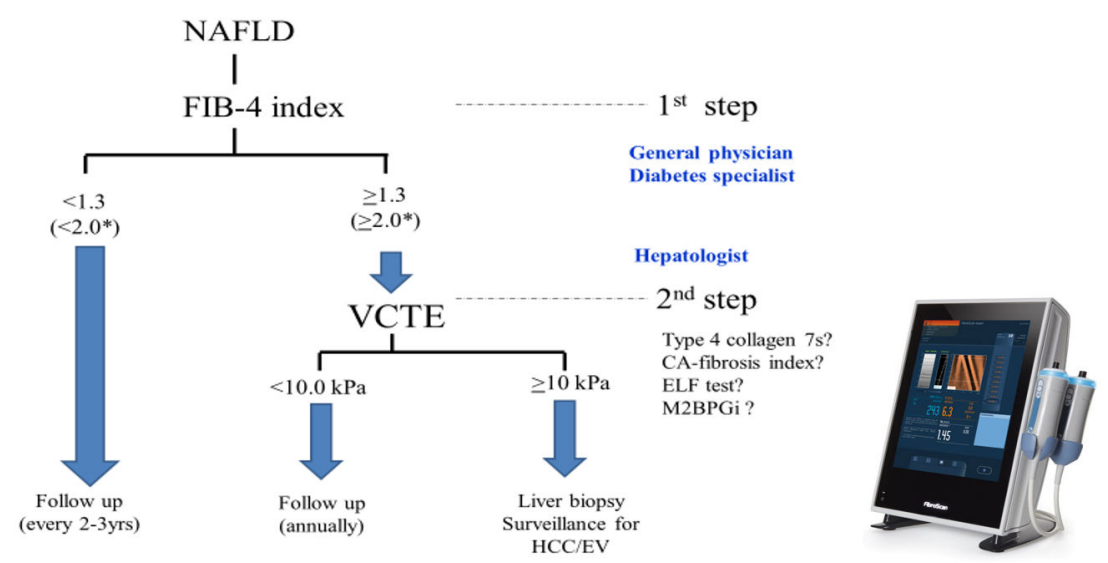

Figure 1. Two-step algorithm for determining NAFLD using the FIB-4 index (first step) and vibration-controlled transient elastography (VCTE) (second step). * older patients (aged 60 to 70 years or older); NAFLD: nonalcoholic fatty liver disease, FIB-4: fibrosis-4, VCTE: vibration-controlled transient elastography, ELF: enhanced liver fibrosis, M2BPGi: Mac-2 binding protein glycan isomer, HCC hepatocellular carcinoma, EV: esophageal varices.

The enhanced liver fibrosis (ELF) test is a non-invasive blood test that measures three direct markers of fibrosis: hyaluronic acid (HA), procollagen III amino-terminal peptide (PIIINP), and tissue inhibitor of matrix metalloproteinase 1 (TIMP-1) [98]. According to a two-step algorithm from EU [113], ELF test can be applied to the intermediate group of FIB-4 index (1.3-3.25). If NAFLD patients have an ELF score of 10.35 or above, they are likely to have advanced fibrosis [113]. Recently, the usefulness of ELF test was validated in a Japanese NAFLD population [118]. Combinations or sequential procedures using VCTE complement the diagnostic performance of ELF testing for the identification of advanced fibrosis. On the view of economic cost, the combination of FIB-4 index plus ELF test is superior to the combination of FIB-4 index plus VCTE [119]. Although ELF test will be covered by health insurance in Japan around 2021, most hepatologists have little knowledge about ELF tests. External validation studies in an international multi-institutional setting are required to confirm this algorithm as shown in Figure 1. It remains unknown whether the genetic variant PNPLA3 I148M may complement these NITs for NAFLD surveillance.

Recently, we constructed artificial intelligent (AI) systems for screening NAFLD and staging fibrosis. These systems might be very useful in clinical practice, including for medical health check-up programs and epidemiological studies of NAFLD, and they certainly significantly reduce medical costs in clinical medicine related to NAFLD. We are now planning to construct these AI systems using Western patients with NAFLD.

\section{Risk Factors of Rapid Fibrosis Progression in NAFLD}

A notable minority of patients with NAFLD progress to more advanced disease that is characterized by NASH and subsequent fibrosis and cirrhosis. To date, there are few high-quality prospective data on the progression of NAFLD. Risk factors of rapid fibrosis progression in NAFLD includes the existence of NASH [120], age [2,120], severe obesity [117,121,122], high fructose consumption [123], insulin resistance [3], presence of T2D [2,17], high HbA1c levels [124], menopause in women [125,126], high ALT levels [127,128], and PNPLA3 G allele [129]. NAFLD progression is influenced by a combination of genetic and environmental factors. 


\section{Message to General Physicians for Avoiding Misdiagnosis of NASH with Severe Fibrosis}

First of all, general physicians determine AST, ALT, and platelet count for calculating FIB-4 index in NAFLD patients. Auto-calculator is uploaded in Japan Society of Hepatology (https: //www.eapharma.co.jp/medicalexpert/product/livact/fib-4/calculator.html). NAFLD patients with a low FIB-4 index score can be followed up. However, coexisting metabolic diseases (T2D, dyslipidemia, and hypertension) should be appropriately treated in those patients. FIB-4 index can be determined every 2 or 3 years. NAFLD patients with intermediate FIB-4 index scores should be considered to perform VCTE or refer to hepatologists. NAFLD patients with a high FIB-4 index should be immediately referred to hepatologists for screening of HCC and esophageal varices. Two-step algorithm using the FIB-4 index as the first step for excluding advanced fibrosis in primary care could reduce unnecessary overreferral and increase case-finding of patients at risk of complications of liver disease. Three parameters including ALT, body weight, and $\mathrm{HbA1c}(\mathrm{ABC})$ should be strictly controlled for prevention of fibrosis progression in NAFLD [130].

\section{Conclusions}

Recently, NAFLD has received much attention in many countries, including Japan. Improving NITs or imaging modalities for screening NAFLD/NASH and staging liver fibrosis in NASH might clarify the epidemiology and prognosis of fatty liver in patients with diabetes. Furthermore, the genetic variant PNPLA3 I148M may complement these NITs for NAFLD surveillance [33,65]. Improving survival in patients with NAFLD requires collaboration between hepatologists and general physicians or diabetes specialists.

Funding: This research is supported by AMED under Grant Number JP19fk0210040 (T.O., Y.S. and M.Y.) and MEXT Grant-in-Aid for Scientific Research (S) Grant number 16H06389 (T.O.).

Conflicts of Interest: All authors have nothing declaration of interests. The funders had no role in the design of the study; in the collection, analyses, or interpretation of data; in the writing of the manuscript, or in the decision to publish the results.

\begin{tabular}{|c|c|}
\hline \multicolumn{2}{|c|}{ Abbreviations } \\
\hline AASLD & American Association for the Study of Liver Diseases \\
\hline $\mathrm{AE}$ & adverse event \\
\hline ALT & alanine aminotransferase \\
\hline AST & aspartate aminotransferase \\
\hline BMI & body mass index \\
\hline $\mathrm{CI}$ & confidence interval \\
\hline CRP & C-reactive protein \\
\hline DLD & diabetic liver disease \\
\hline DPP-4 & dipeptidyl peptidase- 4 \\
\hline ELF & enhanced liver fibrosis \\
\hline FIB-4 & fibrosis- 4 \\
\hline $\mathrm{HCC}$ & hepatocellular carcinoma \\
\hline HR & hazard ratio \\
\hline JAZF1 & juxtaposed with another zinc finger gene 1 \\
\hline MRE & magnetic resonance elastography \\
\hline MRI-PDFF & magnetic resonance imaging-proton density fat fraction \\
\hline NAFLD & nonalcoholic fatty liver disease \\
\hline NASH & nonalcoholic steatohepatitis \\
\hline NAS & NAFLD activity score \\
\hline NFS & NAFLD fibrosis score \\
\hline NIT & non-invasive test \\
\hline OGTT & oral glucose tolerance test \\
\hline OR & odds ratio \\
\hline
\end{tabular}


PNPLA3 patatin-like phospholipase-3

RR risk ratio

SMR standardized mortality rate

T2D type 2 diabetes

TRX thioredoxin

\section{References}

1. Simeone, J.C.; Bae, J.P.; Hoogwerf, B.J.; Sli, Q.; Haupt, A.; Ali, A.K.; Boardman, M.K.; Nordstrom, B.L. Clinical course of nonalcoholic fatty liver disease: An assessment of severity, progression, and outcomes. Clin. Epidemiol. 2017, 9, 679-688. [CrossRef] [PubMed]

2. Nakahara, T.; Hyogo, H.; Yoneda, M.; Sumida, Y.; Eguchi, Y.; Fujii, H.; Ono, M.; Kawaguchi, T.; Imajo, K.; Aikata, H.; et al. Japan Study Group of Nonalcoholic Fatty Liver Disease. Type 2 diabetes mellitus is associated with the fibrosis severity in patients with nonalcoholic fatty liver disease in a large retrospective cohort of Japanese patients. J. Gastroenterol. 2014, 49, 1477-1484. [CrossRef] [PubMed]

3. Fujii, H.; Imajo, K.; Yoneda, M.; Nakahara, T.; Hyogo, H.; Takahashi, H.; Hara, T.; Tanaka, S.; Sumida, Y.; Eguchi, Y.; et al. Japan Study Group of Nonalcoholic Fatty Liver Disease. HOMA-IR: An independent predictor of advanced liver fibrosis in nondiabetic non-alcoholic fatty liver disease. J. Gastroenterol. Hepatol. 2019, 34, 1390-1395.

4. Targher, G.; Marchesini, G.; Byrne, C.D. Risk of type 2 diabetes in patients with non-alcoholic fatty liver disease: Causal association or epiphenomenon? Diabetes Metab. 2016, 42, 142-156. [CrossRef]

5. Younossi, Z.M.; Gramlich, T.; Matteoni, C.A.; Boparai, N.; McCullough, A.J. Nonalcoholic fatty liver disease in patients with type 2 diabetes. Clin. Gastroenterol. Hepatol. 2004, 2, 262-265. [CrossRef]

6. Targher, G.; Bertolini, L.; Zoppini, G.; Rodella, S.; Tessari, R.; Zenari, L.; Day, C.; Arcaro, G. Prevalence of nonalcoholic fatty liver disease and its association with cardiovascular disease among type 2 diabetic patients. Diabetes Care 2007, 30, 1212-1218. [CrossRef]

7. Ong, J.P.; Pitts, A.; Younossi, Z.M. Increased overall mortality and liver-related mortality in non-alcoholic fatty liver disease. J. Hepatol. 2008, 49, 608-612. [CrossRef]

8. Lee, S.B.; Park, G.M.; Lee, J.Y.; Lee, B.U.; Park, J.H.; Kim, B.G.; Jung, S.W.; Jeong, I.D.; Bang, S.J.; Shin, J.W.; et al. Association between non-alcoholic fatty liver disease and subclinical coronary atherosclerosis: An observational cohort study. J. Hepatol. 2018, 68, 1018-1024. [CrossRef]

9. Käräjämäki, A.J.; Pätsi, O.P.; Savolainen, M.; Kesäniemi, Y.A.; Huikuri, H.; Ukkola, O. Non-Alcoholic Fatty Liver Disease as a Predictor of Atrial Fibrillation in Middle-Aged Population (OPERA Study). PLoS ONE 2015, 10, e0142937. [CrossRef]

10. Mantovani, A.; Pernigo, M.; Bergamini, C.; Bonapace, S.; Lipari, P.; Pichiri, I.; Bertolini, L.; Valbusa, F.; Barbieri, E.; Zoppini, G.; et al. Nonalcoholic fatty liver disease is independently associated with early left ventricular diastolic dysfunction in patients with type 2 diabetes. PLoS ONE 2015, 10, e0135329. [CrossRef]

11. Chung, G.E.; Lee, J.H.; Lee, H.; Kim, M.K.; Yim, J.Y.; Choi, S.Y.; Kim, Y.J.; Yoon, J.H.; Kim, D. Nonalcoholic fatty liver disease and advanced fibrosis are associated with left ventricular diastolic dysfunction. Atherosclerosis 2018, 272, 137-144. [CrossRef] [PubMed]

12. Hotta, N.; Nakamura, J.; Iwamoto, Y.; Ohno, Y.; Kasuga, M.; Kikkawa, R.; Toyota, T. Cause of death in Japanese Diabetics based on the results of a survey of 18,385 diabetes during 1991-2000-Reports of committee on cause of death in diabetes mellitus. J. Jpn. Diabetes Soc. 2007, 50, 47-61.

13. Nakamura, J.; Kamiya, H.; Haneda, M.; Inagaki, N.; Tanizawa, Y.; Araki, E.; Ueki, K.; Nakayama, T. Causes of death in Japanese patients with diabetes based on the results of a survey of 45,708 cases during 2001-2010: Report of the Committee on Causes of Death in Diabetes Mellitus. J. Diabetes Investig. 2017, 8, 397-410. [CrossRef] [PubMed]

14. Eguchi, Y.; Hyogo, H.; Ono, M.; Mizuta, T.; Ono, N.; Fujimoto, K.; Chayama, K.; Saibara, T.; JSG-NAFLD. Prevalence and associated metabolic factors of nonalcoholic fatty liver disease in the general population from 2009 to 2010 in Japan: A multicenter large retrospective study. J. Gastroenterol. 2012, 47, 586-595. [PubMed] 
15. Nishioji, K.; Mochizuki, N.; Kobayashi, M.; Kamaguchi, M.; Sumida, Y.; Nishimura, T.; Yamaguchi, K.; Kadotani, H.; Itoh, Y. The Impact of PNPLA3 rs738409 Genetic Polymorphism and Weight Gain $\geq 10 \mathrm{~kg}$ after Age 20 on Non-Alcoholic Fatty Liver Disease in Non-Obese Japanese Individuals. PLoS ONE 2015, 10, e0140427. [CrossRef]

16. Eguchi, Y.; Wong, G.; Akhtar, O.; Sumida, Y. Epidemiology of nonalcoholic fatty liver disease and nonalcoholic steatohepatitis in Japan: A focused literature review. JGH Open 2020, in press. [CrossRef]

17. Younossi, Z.; Anstee, Q.M.; Marietti, M.; Hardy, T.; Henry, L.; Eslam, M.; George, J.; Bugianesi, E. Global burden of NAFLD and NASH: Trends, predictions, risk factors and prevention. Nat. Rev. Gastroenterol. Hepatol. 2018, 15, 11-20. [CrossRef]

18. Sumida, Y.; Niki, E.; Naito, Y.; Yoshikawa, T. Involvement of free radicals and oxidative stress in NAFLD/NASH. Free Radic. Res. 2013, 47, 869-880. [CrossRef]

19. Sumida, Y.; Nakashima, T.; Yoh, T.; Furutani, M.; Hirohama, A.; Kakisaka, Y.; Nakajima, Y.; Ishikawa, H.; Mitsuyoshi, H.; Okanoue, T.; et al. Serum thioredoxin levels as a predictor of steatohepatitis in patients with nonalcoholic fatty liver disease. J. Hepatol. 2003, 38, 32-38. [CrossRef]

20. Sanyal, A.J.; Chalasani, N.; Kowdley, K.V.; McCullough, A.; Diehl, A.M.; Bass, N.M.; Neuschwander-Tetri, B.A.; Lavine, J.E.; Tonascia, J.; Unalp, A.; et al. Pioglitazone, vitamin E, or placebo for nonalcoholic steatohepatitis. N. Engl. J. Med. 2010, 362, 1675-1685. [CrossRef]

21. Sato, K.; Gosho, M.; Yamamoto, T.; Kobayashi, Y.; Ishii, N.; Ohashi, T.; Nakade, Y.; Ito, K.; Fukuzawa, Y.; Yoneda, M. Vitamin E has a beneficial effect on nonalcoholic fatty liver disease: A meta-analysis of randomized controlled trials. Nutrition 2015, 31, 923-930. [CrossRef] [PubMed]

22. Honda, Y.; Kessoku, T.; Sumida, Y.; Kobayashi, T.; Kato, T.; Ogawa, Y.; Tomeno, W.; Imajo, K.; Fujita, K.; Yoneda, M.; et al. Efficacy of glutathione for the treatment of nonalcoholic fatty liver disease: An open-label, single-arm, multicenter, pilot study. BMC Gastroenterol. 2017, 17, 96. [CrossRef] [PubMed]

23. Merat, S.; Malekzadeh, R.; Sohrabi, M.R.; Sotoudeh, M.; Rakhshani, N.; Sohrabpour, A.A.; Naserimoghadam, S. Probucol in the treatment of non-alcoholic steatohepatitis: A double-blind randomized controlled study. J. Hepatol. 2003, 38, 414-418. [CrossRef]

24. Du, J.; Ma, Y.Y.; Yu, C.H.; Li, Y.M. Effects of pentoxifylline on nonalcoholic fatty liver disease: A meta-analysis. World J. Gastroenterol. 2014, 20, 569-577. [CrossRef]

25. Browing, J.D.; Szczepaniak, L.S.; Dobbins, R.; Nuremberg, P.; Horton, J.D.; Cohen, J.C.; Grundy, S.M.; Hobbs, H.H. Prevalence of hepatic steatosis in an urban population in the United States: Impact of ethnicity. Hepatology 2004, 40, 1387-1395. [CrossRef]

26. Hamaguchi, M.; Kojima, T.; Itoh, Y.; Harano, Y.; Fujii, K.; Nakajima, T.; Kato, T.; Takeda, N.; Okuda, J.; Ida, K.; et al. The severity of ultrasonographic findings in nonalcoholic fatty liver disease reflects the metabolic syndrome and visceral fat. Am. J. Gastroenterol. 2007, 102, 2708-2715. [CrossRef]

27. Bril, F.; Ortiz-Lopez, C.; Lomonaca, R.; Orsak, B.; Freckleton, M.; Chintapalli, K.; Hardies, J.; Lai, S.; Solano, F.; Tio, F.; et al. Clinical value of liver ultrasound for the diagnosis of nonalcoholic fatty liver disease in overweight and obese patients. Liver Int. 2015, 35, 2139-2146. [CrossRef] [PubMed]

28. Younossi, Z.M.; Golabi, P.; de Avila, L.; Paik, J.M.; Srishord, M.; Fukui, N.; Qiu, Y.; Burns, L.; Afendy, A.; Nader, F. The global epidemiology of NAFLD and NASH in patients with type 2 diabetes: A systematic review and meta-analysis. J. Hepatol. 2019, 71, 793-801. [CrossRef] [PubMed]

29. Amiri Dash Atan, N.; Koushki, M.; Motedayen, M.; Dousti, M.; Sayehmiri, F.; Vafaee, R.; Norouzinia, M.; Gholami, R. Type 2 diabetes mellitus and non-alcoholic fatty liver disease: A systematic review and meta-analysis. Gastroenterol. Hepatol. Bed Bench 2017, 10 (Suppl. 1), S1-S7. [PubMed]

30. Dai, W.; Ye, L.; Liu, A.; Wen, S.W.; Deng, J.; Wu, X.; Lai, Z. Prevalence of nonalcoholic fatty liver disease in patients with type 2 diabetes mellitus: A meta-analysis. Medicine (Baltimore) 2017, 96, e8179. [CrossRef]

31. Japan Society Ningen Dock. The report of 2008 National Summary of Ningen Dock. The 50th Scientific Meeting of Japan Society of Ningen Dock. Off. J. Jpn. Soc. Ningen Dock 2009, 24, 322. (In Japanese)

32. Kojima, S.; Watanabe, N.; Numata, M.; Ogawa, T.; Matsuzaki, S. Increase in the prevalence of fatty liver in Japan over the past 12 years: Analysis of clinical background. J. Gastroenterol. 2003, 38, 954-961. [CrossRef] [PubMed]

33. Kawaguchi, T.; Shima, T.; Mizuno, M.; Mitsumoto, Y.; Umemura, A.; Kanbara, Y.; Tanaka, S.; Sumida, Y.; Yasui, K.; Takahashi, M.; et al. Risk estimation model for nonalcoholic fatty liver disease in the Japanese using multiple genetic markers. PLoS ONE 2018, 13, e0185490. [CrossRef] [PubMed] 
34. Petit, J.M.; Guiu, B.; Masson, D.; Duvillard, L.; Jooste, V.; Buffier, P.; Bouillet, B.; Brindisi, M.C.; Robin, I.; Gambert, P.; et al. PNPLA3 polymorphism influences liver fibrosis in unselected patients with type 2 diabetes. Liver Int. 2011, 31, 1332-1336. [CrossRef]

35. Farrell, G.C.; Wong, V.W.; Chitturi, S. NAFLD in Asia-As common and important as in the West. Nat. Rev. Gastroenterol. Hepatol. 2013, 10, 307-318. [CrossRef]

36. Welfare MoHLa. National Health and Nutrition Examination Survey. Available online: https://www.nibiohn. go.jp/eiken/kenkounippon21/en/eiyouchousa/ (accessed on 17 June 2020).

37. Anstee, Q.M.; Targher, G.; Day, C.P. Progression of NAFLD to diabetes mellitus, cardiovascular disease or cirrhosis. Nat. Rev. Gastroenterol. Heaptol. 2013, 10, 330-344. [CrossRef]

38. Adams, L.A.; Anstee, Q.M.; Tilg, H.; Targher, G. Non-alcoholic fatty liver disease and its relationship with cardiovascular disease and other extrahepatic disease. Gut 2017, 66, 1138-1153. [CrossRef]

39. Ballestri, Z.; Zona, S.; Targher, G.; Romagnoli, D.; Baldelli, E.; Nascimbeni, F.; Roverato, A.; Guaraldi, G.; Lonardo, A. Nonalcoholic fatty liver disease is associated with an almost twofold increased risk of incident type 2 diabetes and metabolic syndrome: Evidence from a systematic review and meta-analysis. J. Gastroenterol. Hepatol. 2016, 31, 936-944. [CrossRef]

40. Miyaaki, H.; Ichikawa, T.; Nakao, K.; Yatsuhashi, H.; Furukawa, R.; Ohba, K.; Omagari, K.; Kusumoto, Y.; Yanagi, K.; Inoue, O.; et al. Clinicopathological study of nonalcoholic fatty liver disease in Japan: The risk factors for fibrosis. Liver Int. 2008, 28, 519-524. [CrossRef]

41. Shima, T.; Uto, H.; Ueki, K.; Takamura, T.; Kohgo, Y.; Kawata, S.; Yasui, K.; Park, H.; Nakamura, N.; Nakatou, T.; et al. Clinicopathological features of liver injury in patients with type 2 diabetes mellitus and comparative study of histologically proven nonalcoholic fatty liver diseases with or without type 2 diabetes mellitus. J. Gastroenterol. 2012, 48, 515-525. [CrossRef]

42. Estes, C.; Anstee, Q.M.; Arias-Loste, M.T.; Bantel, H.; Bellentani, S.; Caballeria, J.; Colombo, M.; Craxi, A.; Crespo, J.; Day, C.P.; et al. Modeling NAFLD disease burden in China, France, Germany, Italy, Japan, Spain, United Kingdom, and United states for the period 2016-2030. J. Hepatol. 2018, 69, 896-904. [CrossRef] [PubMed]

43. Loria, P.; Lonardo, A.; Anania, F. Liver and diabetes. A vicious circle. Hepatol. Res. 2013, 43, 51-64. [CrossRef] [PubMed]

44. De Marco, R.; Locatelli, F.; Zoppini, G.; Verlato, G.; Bonora, E.; Muggeo, M. Cause specific mortality in type 2 diabetes. The Verona Diabetes Study. Diabetes Care 1999, 22, 756-761. [CrossRef] [PubMed]

45. Campell, P.T.; Newton, C.C.; Patel, A.V.; Jacobs, E.J.; Gapstur, S.M. Diabetes and cause-specific mortality in a prospective cohort of one million U.S. adults. Diabetes Care 2012, 35, 1835-1844. [CrossRef] [PubMed]

46. Zoppini, G.; Fedeli, U.; Gennaro, N.; Saugo, M.; Targher, G.; Bonora, E. Mortality from chronic liver diseases in diabetes. Am. J. Gastroenterol. 2014, 109, 1020-1025. [CrossRef]

47. Giovannucci, E.; Harlan, D.M.; Archer, M.C.; Bergenstal, R.M.; Gapstur, S.M.; Habel, L.A.; Pollak, M.; Regensteiner, J.G.; Yee, D. Diabetes and cancer: A consensus report. Diabetes Care 2010, 33, 1674-1685. [CrossRef]

48. Shima, T.; Uto, H.; Ueki, K.; Kohgo, Y.; Yasui, K.; Nakamura, N.; Nakatou, T.; Takamura, T.; Kawata, S.; Notsumata, K.; et al. Hepatocellular carcinoma as a leading cause of cancer-related deaths in Japanese type 2 diabetes mellitus patients. J. Gastorenterol. 2019, 54, 64-77. [CrossRef]

49. Koh, W.P.; Wang, R.; Jin, A.; Yu, M.C.; Yuan, J.M. Diabetes mellitus and risk of hepatocellular carcinoma: Findings from the Singapore Chinese Health Study. Br. J. Cancer 2013, 108, 1182-1188. [CrossRef]

50. Loomba, R.; Abraham, M.; Unalp, A.; Wilson, L.; Lavine, J.; Doo, E.; Bass, N.M.; Nonalcoholic Steatohepatitis Clinical Research Network. Association between diabetes, family history of diabetes, and risk of nonalcoholic steatohepatitis and fibrosis. Hepatology 2012, 56, 943-951. [CrossRef]

51. Porepa, L.; Ray, J.G.; Sanchez-Romeu, P.; Booth, G.L. Newly diagnosed diabetes mellitus as a risk factor for serious liver disease. CMAJ 2010, 182, E526-E531. [CrossRef]

52. White, D.L.; Kanwal, F.; El-Serag, H.B. Association between nonalcoholic fatty liver disease and risk for hepatocellular cancer, based on systematic review. Clin. Gastroenterol. Hepatol. 2012, 10, 1342-1359. [CrossRef] [PubMed]

53. Chen, C.L.; Yang, H.I.; Yang, W.S.; Liu, C.J.; Chen, P.J.; You, S.L.; Wang, L.Y.; Sun, C.A.; Lu, S.N.; Chen, D.S.; et al. Metabolic factors and risk of hepatocellular carcinoma by chronic hepatitis B/C infection: A follow-up study in Taiwan. Gastroenterology 2008, 135, 111-121. [CrossRef] [PubMed] 
54. Chen, J.; Han, Y.; Xu, C.; Xiao, T.; Wang, B. Effect of type 2 diabetes mellitus on the risk for hepatocellular carcinoma in chronic liver diseases: A meta-analysis of cohort studies. Eur. J. Cancer Prev. 2015, 24, 89-99. [CrossRef] [PubMed]

55. Kawamura, Y.; Arase, Y.; Ikeda, K.; Seko, Y.; Imai, N.; Hosaka, T.; Kobayashi, M.; Saitoh, S.; Sezaki, H.; Akuta, N.; et al. Large-scale long-term follow-up study of Japanese patients with non-alcoholic Fatty liver disease for the onset of hepatocellular carcinoma. Am. J. Gastroenterol. 2012, 107, 253-261. [CrossRef]

56. Seko, Y.; Sumida, Y.; Tanaka, S.; Mori, K.; Taketani, H.; Ishiba, H.; Hara, T.; Okajima, A.; Umemura, A.; Nishikawa, T.; et al. Development of hepatocellular carcinoma in Japanese patients with biopsy-proven non-alcoholic fatty liver disease: Association between PNPLA3 genotype and hepatocarcinogenesis/fibrosis progression. Hepatol. Res. 2017, 47, 1083-1092.

57. Onitilo, A.A.; Engel, J.M.; Glurich, I.; Stankowski, R.V.; Williams, G.M.; Doi, S.A. Diabetes and cancer II: Role of diabetes medications and influence of shared risk factors. Cancer Causes Control 2012, 23, 991-1008. [CrossRef]

58. Walker, J.J.; Johnson, J.A.; Wild, S.H. Diabetes treatments and cancer risk: The importance of considering aspects of drug exposure. Lancet Diabetes Endocrinol. 2013, 1, 132-139. [CrossRef]

59. Kawaguchi, T.; Kohjima, M.; Ichikawa, T.; Seike, M.; Ide, Y.; Mizuta, T.; Honda, K.; Nakao, K.; Nakamuta, M.; Sata, M. The morbidity and associated risk factors of cancer in chronic liver disease patients with diabetes mellitus: A multicenter field survey. J. Gastroenterol. 2015, 50, 333-341. [CrossRef]

60. Kasuga, M.; Ueki, K.; Tajima, N.; Noda, M.; Ohashi, K.; Noto, H.; Goto, A.; Ogawa, W.; Sakai, R.; Tsugane, S.; et al. Report of the Japan Diabetes Society/Japanese Cancer Association Joint Committee on Diabetes and Cancer. Cancer Sci. 2013, 104, 965-976. [CrossRef]

61. Johnson, J.A.; Bowker, S.L. Intensive glycaemic control and cancer risk in type 2 diabetes: A meta-analysis of major trials. Diabetologia 2011, 54, 25-31. [CrossRef]

62. Goto, A.; Noto, H.; Noda, M.; Ueki, K.; Kasuga, M.; Tajima, N.; Ohashi, K.; Sakai, R.; Tsugane, S.; Hamajima, N.; et al. Report of the Japan Diabetes Society (JDS)/Japanese Cancer Association (JCA) Joint Committee on Diabetes and Cancer, Second Report. Diabetol. Int. 2016, 7, 12-15. [CrossRef]

63. Stender, S.; Loomba, R. PNPLA3 Genotype and Risk of Liver and All-Cause Mortality. Hepatology 2020, in press. [CrossRef] [PubMed]

64. Gellert-Kristensen, H.; Richardson, T.G.; Davey, S.G.; Nordestgaard, B.G.; Tybjaerg-Hansen, A.; Stender, S. Combined Effect of PNPLA3, TM6SF2, and HSD17B13 Variants on Risk of Cirrhosis and Hepatocellular Carcinoma in the General Population. Hepatology 2020, in press. [CrossRef] [PubMed]

65. Unalp-Arida, A.; Ruhl, C.E. Patatin-Like Phospholipase Domain-Containing Protein 3 I148M and Liver Fat and Fibrosis Scores Predict Liver Disease Mortality in the U.S. Population. Hepatology 2020, 71, 820-834. [CrossRef] [PubMed]

66. Ueyama, M.; Nishida, N.; Korenaga, M.; Korenaga, K.; Kumagai, E.; Yanai, H.; Adachi, H.; Katsuyama, H.; Moriyama, S.; Hamasaki, H.; et al. The impact of PNPLA3 and JAZF1 on hepatocellular carcinoma in non-viral hepatitis patients with type 2 diabetes mellitus. J. Gastroenterol. 2016, 51, 370-379. [CrossRef] [PubMed]

67. Hernaez, R.; Lazo, M.; Bonekamp, S.; Kamel, I.; Brancati, F.L.; Guallar, E.; Clark, J.M. Diagnostic accuracy and reliability of ultrasonography for the detection of fatty liver; a meta-analysis. Hepatology 2011, 54, 1082-1090. [CrossRef]

68. Saadeh, S.; Younossi, Z.M.; Remer, E.M.; Gramlich, T.; Ong, J.P.; Hurley, M.; Mullen, K.D.; Cooper, J.N.; Sheridan, M.J. The utility of radiological imaging in nonalcoholic fatty liver disease. Gastroenterology 2002, 123, 745-750. [CrossRef]

69. Tada, T.; Kumada, T.; Toyoda, H.; Kobayashi, N.; Sone, Y.; Oguri, T.; Kamiyama, N. Utility of Attenuation Coefficient Measurement Using an Ultrasound-Guided Attenuation Parameter for Evaluation of Hepatic Steatosis: Comparison with MRI-Determined Proton Density Fat Fraction. Am. J. Roentgenol. 2019, 212, 332-341. [CrossRef]

70. Bedogni, G.; Bellentani, S.; Miglioli, L.; Masutti, F.; Passalacqua, M.; Castiglione, A.; Tiribelli, C. The Fatty Liver Index: A simple and accurate predictor of hepatic steatosis in the general population. BMC Gastroenterol. 2006, 6, 33. [CrossRef] 
71. Poynard, T.; Ratziu, V.; Naveau, S.; Thabut, D.; Charlotte, F.; Messous, D.; Capron, D.; Abella, A.; Massard, J.; Ngo, Y.; et al. The diagnostic value of biomarkers (SteatoTest) for the prediction of liver steatosis. Comp. Hepatol. 2005, 4, 10. [CrossRef]

72. Kotronen, A.; Peltonen, M.; Hakkarainen, A.; Sevastianova, K.; Bergholm, R.; Johansson, L.M.; Lundbom, N.; Rissanen, A.; Ridderstråle, M.; Groop, L.; et al. Prediction of non-alcoholic fatty liver disease and liver fat using metabolic and genetic factors. Gastroenterology 2009, 137, 865-872. [CrossRef]

73. Fedchuk, L.; Nascimbeni, F.; Pais, R.; Charlotte, F.; Housset, C.; Ratziu, V.; LIDO Study Group. Performance and limitations of steatosis biomarkers in patients with nonalcoholic fatty liver disease. Aliment. Pharmacol. Ther. 2014, 40, 1209-1222. [CrossRef] [PubMed]

74. Zhu, J.; He, M.; Zhang, Y.; Li, T.; Liu, Y.; Xu, Z.; Chen, W. Validation of simple indexes for nonalcoholic fatty liver disease in western China: A retrospective cross-sectional study. Endocr. J. 2018, 65, 373-381. [CrossRef] [PubMed]

75. Hirata, A.; Sugiyama, D.; Kuwabara, K.; Hirata, T.; Tsutatani, H.; Funamoto, M.; Watanabe, K.; Miyamatsu, N.; Okamura, T. Fatty liver index predicts incident diabetes in a Japanese general population with and without impaired fasting glucose. Hepatol. Res. 2018, 48, 708-716. [CrossRef] [PubMed]

76. Lee, J.H.; Kim, D.; Kim, H.J.; Lee, C.H.; Yang, J.I.; Kim, W.; Kim, Y.J.; Yoon, J.H.; Cho, S.H.; Sung, M.W.; et al. Hepatic steatosis index: A simple screening tool reflecting nonalcoholic fatty liver disease. Dig. Liver Dis. 2010, 42, 503-508. [CrossRef]

77. Prati, D.; Taioli, E.; Zenalla, A.; Della Torre, E.; Butelli, S.; Del Vecchio, E.; Vianello, L.; Zanuso, F.; Mozzi, F.; Milani, S.; et al. Updated definition of healthy ranges for serum alanine aminotransferase levels. Ann. Intern. Med. 2002, 137, 1-10. [CrossRef]

78. Kwo, P.Y.; Cohen, S.M.; Lim, J.K. ACG Clinical Guideline: Evaluation of abnormal liver chemistries. Am. J. Gastroenterol. 2017, 112, 18-35. [CrossRef]

79. Dulai, P.S.; Singh, S.; Patel, J.; Soni, M.; Prokop, L.J.; Younossi, Z.; Sebastiani, G.; Ekstedt, M.; Hagstrom, H.; Nasr, P.; et al. Increased risk of mortality by fibrosis stage in nonalcoholic fatty liver disease: Systematic review and meta-analysis. Hepatology 2017, 65, 1557-1565. [CrossRef]

80. Singh, A.; Gosai, F.; Siddiqui, M.T.; Gupta, M.; Lopez, R.; Lawitz, E.; Poordad, F.; Carey, W.; McCullough, A.; Alkhouri, N. Accuracy of Noninvasive Fibrosis Scores to Detect Advanced Fibrosis in Patients With Type-2 Diabetes With Biopsy-proven Nonalcoholic Fatty Liver Disease. J. Clin. Gastroenterol. 2020, in press. [CrossRef]

81. Sumida, Y.; Yoneda, M.; Tokushige, K.; Kawanaka, M.; Fujii, H.; Yoneda, M.; Imajo, K.; Takahashi, H.; Eguchi, Y.; Ono, M.; et al. Japan Study Group of NAFLD (JSG-NAFLD). Estimated Prevalence of Advanced Hepatic Fibrosis by Elastography in Patients with Type 2 Diabetes. Interv. Obes. Diabetes 2020, 3, 287-293.

82. Sumida, Y.; Eguchi, Y.; Ono, M. Current status and agenda in the diagnosis of nonalcoholic steatohepatitis in Japan. World J. Hepatol. 2010, 2, 374-383. [CrossRef]

83. Sumida, Y.; Nakajima, A.; Itoh, Y. Limitations of liver biopsy and non-invasive diagnostic tests for the diagnosis of nonalcoholic fatty liver disease/nonalcoholic steatohepatitis. World J. Gastroenterol. 2014, 20, 475-485. [CrossRef]

84. Vilar-Gomez, E.; Chalasani, N. Non-invasive assessment of no-alcoholic fatty liver disease: Clinical prediction rules and blood-based biomarkers. J. Hepatol. 2018, 68, 305-315. [CrossRef]

85. Chalasani, N.; Younossi, Z.; Lavine, J.E.; Charlton, M.; Cusi, K.; Rinella, M.; Harrison, S.A.; Brunt, E.M.; Sanyal, A.J. The diagnosis and management of nonalcoholic fatty liver disease: Practice guidance from the American Association for the Study of Liver Diseases. Hepatology 2018, 67, 328-357. [CrossRef] [PubMed]

86. Angulo, P.; Hui, J.M.; Marchesini, G.; Bugianesi, E.; George, J.; Farrell, G.C.; Enders, F.; Saksena, S.; Burt, A.D.; Bida, J.P.; et al. The NAFLD fibrosis score: A noninvasive system that identifies liver fibrosis in patients with NAFLD. Hepatology 2007, 45, 846-854. [CrossRef] [PubMed]

87. Shah, A.G.; Lydecker, A.; Murray, K.; Tetri, B.N.; Contos, M.J.; Sanyal, A.J.; Nash Clinical Research Network. Comparison of noninvasive markers of fibrosis in patients with nonalcoholic fatty liver disease. Clin. Gastroenterol. Hepatol. 2009, 7, 1104-1112. [CrossRef] [PubMed]

88. Sumida, Y.; Yoneda, M.; Hyogo, H.; Itoh, Y.; Ono, M.; Fujii, H.; Eguchi, Y.; Suzuki, Y.; Aoki, N.; Kanemasa, K.; et al. Japan Study Group of Nonalcoholic Fatty Liver Disease (JSG-NAFLD). Validation of the FIB4 index in a Japanese nonalcoholic fatty liver disease population. BMC Gastroenterol. 2012, 12, 2. [CrossRef] 
89. Chan, W.K.; Treeprasertsuk, S.; Goh, G.B.; Fan, J.G.; Song, M.J.; Charatcharoenwitthaya, P.; Duseja, A.; Dan, Y.Y.; Imajo, K.; Nakajima, A.; et al. Optimizing Use of Nonalcoholic Fatty Liver Disease Fibrosis Score, Fibrosis-4 Score, and Liver Stiffness Measurement to Identify Patients with Advanced Fibrosis. Clin. Gastroenterol. Hepatol. 2019, 17, 2570-2580. [CrossRef]

90. McPherson, S.; Hardy, T.; Dufour, J.F.; Petta, S.; Romero-Gomez, M.; Allison, M.; Oliveira, C.P.; Francque, S.; Van Gaal, L.; Schattenberg, J.; et al. Age as a Confounding Factor for the Accurate Non-Invasive Diagnosis of Advanced NAFLD Fibrosis. Am. J. Gastroenterol. 2017, 112, 740-751. [CrossRef]

91. Ishiba, H.; Sumida, Y.; Tanaka, S.; Yoneda, M.; Hyogo, H.; Ono, M.; Fujii, H.; Eguchi, Y.; Suzuki, Y.; Yoneda, M.; et al. Japan Study Group of Non-Alcoholic Fatty Liver Disease (JSG-NAFLD). The novel cutoff points for the FIB4 index categorized by age increase the diagnostic accuracy in NAFLD: A multi-center study. J. Gastroenterol. 2018, 53, 1216-1224. [CrossRef]

92. Ishiba, Y.; Sumida, Y.; Tanaka, S.; Yoneda, M.; Hyogo, H.; Ono, M.; Fujii, H.; Eguchi, Y.; Suzuki, Y.; Yoneda, M.; et al. Type IV collagen 7S is the most accurate test for identifying advanced fibrosis in non-alcoholic fatty liver disease with type 2 diabetes. Diabetes Care 2020, submitted.

93. Shah, S.; Dhami-Shah, H.; Kamble, S.; Shukla, A. FIB-4 cut-off of 1.3 may be inappropriate in a primary care referral pathway for patients with non-alcoholic fatty liver disease. J. Hepatol. 2020, 73, 212-214. [CrossRef] [PubMed]

94. Newsome, P.N.; Sasso, M.; Deeks, J.J.; Paredes, A.; Boursier, J.; Chan, W.K.; Yilmaz, Y.; Czernichow, S.; Zheng, M.H.; Wong, V.W.; et al. FibroScan-AST (FAST) score for the non-invasive identification of patients with non-alcoholic steatohepatitis with significant activity and fibrosis: A prospective derivation and global validation study. Lancet Gastroenterol. Hepatol. 2020, 5, 362-373. [CrossRef]

95. Oeda, S.; Takahashi, H.; Imajo, K.; Seko, Y.; Kobayashi, T.; Ogawa, Y.; Moriguchi, M.; Yoneda, M.; Anzai, K.; Irie, H.; et al. Diagnostic accuracy of FibroScan-AST score to identify non-alcoholic steatohepatitis with significant activity and fibrosis in Japanese patients with non-alcoholic fatty liver disease: Comparison between $\mathrm{M}$ and XL probes. Hepatol. Res. 2020, in press. [CrossRef] [PubMed]

96. Yoshimura, K.; Okanoue, T.; Ebise, H.; Iwasaki, T.; Mizuno, M.; Shima, T.; Ichihara, J.; Yamazaki, K. Identification of novel noninvasive markers for diagnosing nonalcoholic steatohepatitis and related fibrosis by data mining. Hepatology 2016, 63, 462-473. [CrossRef] [PubMed]

97. Okanoue, T.; Ebise, H.; Kai, T.; Mizuno, M.; Shima, T.; Ichihara, J.; Aoki, M. A simple scoring system using type IV collagen $7 \mathrm{~s}$ and aspartate aminotransferase for diagnosing nonalcoholic steatohepatitis and related fibrosis. J. Gastroenterol. 2018, 53, 129-139. [CrossRef]

98. Guha, I.N.; Parkes, J.; Roderick, P.; Chattopadhyay, D.; Cross, R.; Harris, S.; Kaye, P.; Burt, A.D.; Ryder, S.D.; Aithal, G.P.; et al. Noninvasive markers of fibrosis in nonalcoholic fatty liver disease: Validating the European Liver Fibrosis Panel and exploring simple markers. Hepatology 2008, 47, 455-460. [CrossRef]

99. Sumida, Y.; Yoneda, M.; Hyogo, H.; Yamaguchi, K.; Ono, M.; Fujii, H.; Eguchi, Y.; Suzuki, Y.; Imai, S.; Kanemasa, K.; et al. Japan Study Group of Nonalcoholic Fatty Liver Disease (JSG-NAFLD). A simple clinical scoring system using ferritin, fasting insulin, and type IV collagen 7S for predicting steatohepatitis in nonalcoholic fatty liver disease. J. Gastroenterol. 2011, 46, 257-268. [CrossRef]

100. Shimada, M.; Kawahara, H.; Ozaki, K.; Fukura, M.; Yano, H.; Tsuchishima, M.; Tsutsumi, M.; Takase, S. Usefulness of a combined evaluation of the serum adiponectin level, HOMA-IR, and serum type IV collagen 7S level to predict the early stage of nonalcoholic steatohepatitis. Am. J. Gastroenterol. 2007, 102, 1931-1938. [CrossRef]

101. Yoneda, M.; Mawatari, H.; Fujita, K.; Yonemitsu, K.; Kato, S.; Takahashi, H.; Kirikoshi, H.; Inamori, M.; Nozaki, Y.; Abe, Y.; et al. Type IV collagen 7s domain is an independent clinical marker of the severity of fibrosis in patients with nonalcoholic steatohepatitis before the cirrhotic stage. J. Gastroenterol. 2007, 42, 375-381. [CrossRef]

102. Eddowes, P.J.; Sasso, M.; Allison, M.; Tsochatzis, E.; Anstee, Q.M.; Sheridan, D.; Guha, I.N.; Cobbold, J.F.; Deeks, J.J.; Paradis, V.; et al. Accuracy of Fibro Scan controlled attenuation parameter and liver stiffness measurement in assessing steatosis and fibrosis in patients with nonalcoholic fatty liver disease. Gastroenterology 2019, 156, 1717-1730. [CrossRef] [PubMed] 
103. Siddiqui, M.S.; Vuppalanchi, R.; Van Natta, M.L.; Hallinan, E.; Kowdley, K.V.; Abdelmalek, M.; Neuschwander-Tetri, B.A.; Loomba, R.; Dasarathy, S.; Brandman, D.; et al. Vibration-controlled transient elastography to assess fibrosis and steatosis in patient with nonalcoholic fatty liver disease. Clin. Gastroenterol. Hepatol. 2019, 17, 156-163. [CrossRef] [PubMed]

104. Yoneda, M.; Yoneda, M.; Mawatari, H.; Fujita, K.; Endo, H.; Iida, H.; Nozaki, Y.; Yonemitsu, K.; Higurashi, T.; Takahashi, H.; et al. Noninvasive assessment of liver fibrosis by measurement of stiffness in patients with nonalcoholic fatty liver disease (NAFLD). Dig. Liver Dis. 2008, 40, 371-378. [CrossRef] [PubMed]

105. Okajima, A.; Sumida, Y.; Taketani, H.; Hara, T.; Seko, Y.; Ishiba, H.; Nishimura, T.; Umemura, A.; Nishikawa, T.; Yamaguchi, K.; et al. Liver stiffness measurement to platelet ratio index predicts the stage of liver fibrosis in non-alcoholic fatty liver disease. Hepatol. Res. 2017, 47, 721-730. [CrossRef]

106. Seki, K.; Shima, T.; Oya, H.; Mitsumoto, Y.; Mizuno, M.; Okanoue, T. Assessment of transient elastography in Japanese patients with non-alcoholic fatty liver disease. Hepatol. Res. 2017, 47, 882-889. [CrossRef]

107. Castera, L.; Friedrich-Rust, M.; Loomba, R. Noninvasive Assessment of Liver Disease in Patients with Nonalcoholic Fatty Liver Disease. Gastroenterology 2019, 156, 1264-1281. [CrossRef]

108. Younossi, Z.M.; Loomba, R.; Anstee, Q.M.; Rinella, M.E.; Bugianesi, E.; Marchesini, G.; Neuschwander-Tetri, B.A.; Serfaty, L.; Negro, F.; Caldwell, S.H.; et al. Diagnostic modalities for nonalcoholic fatty liver disease, nonalcoholic steatohepatitis, and associated fibrosis. Hepatology 2018, 68, 349-360. [CrossRef]

109. Shima, T.; Sakai, K.; Oya, H.; Katayama, T.; Mitsumoto, Y.; Mizuno, M.; Kanbara, Y.; Okanoue, T. Diagnostic accuracy of combined biomarker measurement and vibration-controlled transient elastography (VCTE) for predicting fibrosis stage of non-alcoholic fatty liver disease. J. Gastroenterol. 2020, 55, 100-112. [CrossRef]

110. Yoneda, M.; Imajo, K.; Takahashi, H.; Ogawa, Y.; Eguchi, Y.; Sumida, Y.; Yoneda, M.; Kawanaka, M.; Saito, S.; Tokushige, K.; et al. Clinical strategy of diagnosing and following patients with nonalcoholic fatty liver disease based on invasive and noninvasive methods. J. Gastroenterol. 2018, 53, 181-196. [CrossRef]

111. Davyduke, T.; Tandon, P.; Al-Karaghouli, M.; Abraldes, J.G.; Ma, M.M. Impact of Implementing a "FIB-4 First" Strategy on a Pathway for Patients with NAFLD Referred from Primary Care. Hepatol. Commun. 2019, 3, 1322-1333. [CrossRef]

112. Hsu, C.; Caussy, C.; Imajo, K.; Chen, J.; Singh, S.; Kaulback, K.; Le, M.D.; Hooker, J.; Tu, X.; Bettencourt, R.; et al. Magnetic Resonance vs Transient Elastography Analysis of Patients with Nonalcoholic Fatty Liver Disease: A Systematic Review and Pooled Analysis of Individual Participants. Clin. Gastroenterol. Hepatol. 2019, 17, 630-637. [CrossRef] [PubMed]

113. Kim, M.; Jun, D.W.; Park, H.; Kang, B.K.; Sumida, Y. Sequential Combination of FIB-4 Followed by M2BPGi Enhanced Diagnostic Performance for Advanced Hepatic Fibrosis in an Average Risk Population. J. Clin. Med. 2020, 9, 1119. [CrossRef] [PubMed]

114. Srivastava, A.; Gailer, R.; Tanwar, S.; Trembling, P.; Parkes, J.; Rodger, A.; Suri, D.; Thorburn, D.; Sennett, K.; Morgan, S.; et al. Prospective evaluation of a primary care referral pathway for patients with non-alcoholic fatty liver disease. J. Hepatol. 2019, 71, 371-378. [CrossRef] [PubMed]

115. Abe, M.; Miyake, T.; Kuno, A.; Imai, Y.; Sawai, Y.; Hino, K.; Hara, Y.; Hige, S.; Sakamoto, M.; Yamada, G.; et al. Association between Wisteria floribunda agglutinin-positive Mac-2 binding protein and the fibrosis stage of non-alcoholic fatty liver disease. J. Gastroenterol. 2015, 50, 776-784. [CrossRef]

116. Tamaki, N.; Higuchi, M.; Kurosaki, M.; Kirino, S.; Osawa, L.; Watakabe, K.; Wang, W.; Okada, M.; Shimizu, T.; Takaura, K.; et al. Wisteria floribunda agglutinin-positive mac-2 binding protein as an age-independent fibrosis marker in nonalcoholic fatty liver disease. Sci. Rep. 2019, 9, 10109. [CrossRef] [PubMed]

117. Ogawa, Y.; Honda, Y.; Kessoku, T.; Tomeno, W.; Imajo, K.; Yoneda, M.; Kawanaka, M.; Kirikoshi, H.; Ono, M.; Taguri, M.; et al. Wisteria floribunda agglutinin-positive Mac-2-binding protein and type 4 collagen 7S: Useful markers for the diagnosis of significant fibrosis in patients with non-alcoholic fatty liver disease. J. Gastroenterol. Hepatol. 2018, 33, 1795-1803. [CrossRef]

118. Inadomi, C.; Takahashi, H.; Ogawa, Y.; Oeda, S.; Imajo, K.; Kubotsu, Y.; Tanaka, K.; Kessoku, T.; Okada, M.; Isoda, H.; et al. Accuracy of the Enhanced Liver Fibrosis test, and combination of the Enhanced Liver Fibrosis and non-invasive tests for the diagnosis of advanced liver fibrosis in patients with non-alcoholic fatty liver disease. Hepatol. Res. 2020, in press. [CrossRef] 
119. Crossan, C.; Majumdar, A.; Srivastava, A.; Thorburn, D.; Rosenberg, W.; Pinzani, M.; Longworth, L.; Tsochatzis, E.A. Referral pathways for patients with NAFLD based on non-invasive fibrosis tests: Diagnostic accuracy and cost analysis. Liver Int. 2019, 39, 2052-2060. [CrossRef]

120. Singh, S.; Allen, A.M.; Wang, Z.; Prokop, L.J.; Murad, M.H.; Loomba, R. Fibrosis progression in nonalcoholic fatty liver vs. nonalcoholic steatohepatitis: A systematic review and meta-analysis of paired-biopsy studies. Clin. Gastroenterol. Hepatol. 2015, 13, 643-654. [CrossRef]

121. Ratziu, V.; Bellentani, S.; Cortez-Pinto, H.; Day, C.; Marchesini, G. A position statement on NAFLD/NASH based on the EASL 2009 special conference. J. Hepatol. 2010, 53, 372-384. [CrossRef]

122. Schuppan, D.; Surabattula, R.; Wang, X.Y. Determinants of fibrosis progression and regression in NASH. J. Hepatol. 2018, 68, 238-250. [CrossRef] [PubMed]

123. Abdelmalek, M.F.; Suzuki, A.; Guy, C.; Unalp-Arida, A.; Colvin, R.; Johnson, R.J.; Diehl, A.M.; Nonalcoholic Steatohepatitis Clinical Research Network. Increased fructose consumption is associated with fibrosis severity in patients with nonalcoholic fatty liver disease. Hepatology 2010, 51, 1961-1971. [CrossRef] [PubMed]

124. Hamaguchi, E.; Takamura, T.; Sakurai, M.; Mizukoshi, E.; Zen, Y.; Takeshita, Y.; Kurita, S.; Arai, K.; Yamashita, T.; Sasaki, M.; et al. Histological course of nonalcoholic fatty liver disease in Japanese patients: Tight glycemic control, rather than weight reduction, ameliorates liver fibrosis. Diabetes Care 2010, 33, 284-286. [CrossRef]

125. Yoneda, M.; Thomas, E.; Sumida, Y.; Eguchi, Y.; Schiff, E.R. The influence of menopause on the development of hepatic fibrosis in nonobese women with nonalcoholic fatty liver disease. Hepatology 2014, 60, 1792. [CrossRef] [PubMed]

126. Yang, J.D.; Abdelmalek, M.F.; Pang, H.; Guy, C.D.; Smith, A.D.; Diehl, A.M.; Suzuki, A. Gender and menopause impact severity of fibrosis among patients with nonalcoholic steatohepatitis. Hepatology 2014, 59, 1406-1414. [CrossRef]

127. Hoofnagle, J.H.; Van Natta, M.L.; Kleiner, D.E.; Clark, J.M.; Kowdley, K.V.; Loomba, R.; Neuschwander-Tetri, B.A.; Sanyal, A.J.; Tonascia, J.; Non-alcoholic Steatohepatitis Clinical Research Network (NASH CRN). Vitamin E and changes in serum alanine aminotransferase levels in patients with non-alcoholic steatohepatitis. Aliment. Pharmacol. Ther. 2013, 38, 134-143.

128. Seko, Y.; Sumida, Y.; Tanaka, S.; Mori, K.; Taketani, H.; Ishiba, H.; Hara, T.; Okajima, A.; Yamaguchi, K.; Moriguchi, M.; et al. Serum alanine aminotransferase predicts the histological course of non-alcoholic steatohepatitis in Japanese patients. Hepatol. Res. 2015, 45, E53-E61. [CrossRef]

129. Eslam, M.; Valenti, L.; Romeo, S. Genetics and epigenetics of NAFLD and NASH: Clinical impact. J. Hepatol. 2018, 68, 268-279. [CrossRef]

130. Sumida, Y.; Yoneda, M. Current and future pharmacological therapies for NAFLD/NASH. J. Gastroenterol. 2018, 53, 362-376. [CrossRef]

(C) 2020 by the authors. Licensee MDPI, Basel, Switzerland. This article is an open access article distributed under the terms and conditions of the Creative Commons Attribution (CC BY) license (http://creativecommons.org/licenses/by/4.0/). 